E3 Journal of Business Management and Economics Vol. 7(2). pp. 038-043 August, 2016

Available online http://www.e3journals.org

ISSN 2141-7482 @ E3 Journals 2016

DOI : http://dx.doi.org/10.18685/EJBME(7)2 EJBME-16-016

Full Length Research Paper

\title{
Constructs and manifestations of glass ceilings in nigerian workplaces
}

\author{
Freeman Oghenerume Orubu ${ }^{1 *}$ and Edafetano Lucky Oboreh ${ }^{1}$ \\ ${ }^{1}$ Department of Business Administration and Management, Delta State Polytechnic, Ozoro, Nigeria
}

Accepted 12 July, 2016

In the quest for equality in Nigerian workplaces, a lot of vices have been brought to light it has been observed that despite the existence of instruments of protection and promotion of gender equality globally, Nigeria has been slow to implementation. This has denied females from fully participating and contributing to labour of Nigeria. The glass ceiling describes invisible but prevalent barriers limiting the progress of minority groups and women within workplaces which engenders emotions in women especially and has been adduced to the development of female roles in organisations despite these groups possessing exceptional qualities and better managerial skills. This could be made manifest in forms of sexual harassment, forms of discrimination, wage differences, victimisation and so on. This paper explores the causes and manifestations and also provide some evidence of these vices against women in Nigerian.

KEYWORDS: Glass ceiling, organisational behaviour, gender equality

\section{INTRODUCTION}

Of recent, there have been concerns on rights of women and minority groups' participation in economic and political activities in Nigeria. Being the largest and most populous nation in Africa, Nigeria has witnessed inconsistencies and contradictions in human resources development in workplaces which has paved way for negative affectivity of minority groups and women. This has in turn spiralled into marginalising these groups and reducing participation in economic activities. According to Ifemeje and Ikpeze (2012), this negative affectivity of minority groups and women is an all pervasive global problem and has frequently lead to intense gender and minority group's inequality worldwide. This inequality has been termed 'glass ceiling' (Stockdale and Crosby. 2004). It is a metaphor that describes invisible but prevalent barriers limiting the progress of minority groups and women within workplaces. It refers to the existence of an unacknowledged situation or limitation barrier preventing the upward advancement of women or minority groups along organisation hierarchy (Songini and Gllan, 2009). This situation usually engenders emotions in women especially and has affected the

*Corresponding Author Email: oruburume@gmail.com development of female roles in organisations despite these groups possessing exceptional qualities and better managerial skills (Owoyemi and Olusanya, 2014).

Glass ceiling is primarily identified as a female gender issue but recent evidence have shown that minority groups are also faced with these barriers as they attempt to move up th organisation hierarchy (US department of Labour, 1997). In Nigeria, with the existence of contradictions in legal systems such as common law, religious laws and traditional beliefs, this phenomenon is predominant in work places and could be made manifest in forms of sexual harassment, forms of discrimination, wage differences, and so on. Women and minority groups are becoming dissatisfied by the continued lack of recognition, flexibility and motivation in their talent needs despite the various degrees of input in work over time (Work Life Company, 2012). This paper explores the probable causes, manifestations and evidence of these vices against women and minority groups in workplaces as well as examines the extent of female and minority group's participation in the Nigerian civil service.

\section{Literature review}

Glass ceiling refers to the existence of an unacknowledged situation or limitation barrier preventing 
the upward advancement of women or minority groups along the organisational hierarchy (Songini and Gnan 2009). This normally refers to a situation where there is an immediate stop in the progression of a qualified person in an orgainsation, these barriers which are usually invisible affect minority groups and women more as it helps in preventing these groups from securing high pay as well as high level management positions (Cotter et al., 2001). The concept of glass ceilings was first used by in 1984 by Nora Frenkiel an editor in the wall street journal calling this point where women reach and get stuck on the top of the middle management 'glass ceiling' (Longo and Strachey 2008). It assumes that the low representation of women in low management positions and decision making is not as a result of choice or failure by a woman but as a consequence of the sociological and structural barriers that exists in organisations which resulted from norms and interactions between participants. (Vaughan and Hogg, 2008). Gilberman, 1998, went further to observe that female managerial style, despite been better has continued to experience incredulity by the male gender and as such have received low ratings.

Glass ceilings exists in part, to links between the male stereotyping in the sense that qualities are being given to males in terms of logical reasoning, strategic, competitive and aggressive decision making (Korac-Kakabdase and Kouzmin, 1997). This barrier reflects discrimination and unequal differential treatment of a group of individuals specifically directed towards women and more recently minority groups. Many share a cultural belief that women are not supposed to be in top level power positions. At the uppermost level, this barrier comes into play, thus stereotyping based on gender of group, despite identical education attainment, ambition, and commitment to career.

\section{Constructs and manifestations}

It defines an artificial barrier existent in organisations and these barriers are based on attitudes and bias preventing individual minority groups and females from advancing into top management positions. (US Dept of Labour, 1991). This has helped greatly in building barriers against women and minority groups in organisations.

\section{Gender based management}

The personification of male gender managerial culture is still an ongoing phenomenon in Nigeria's academic and business settings despite recognized behavioural differences between the male and female gender that none is inferior. To support this argument, Owoyemi and Olusanya, (2014) talked about the same educational training process both gender undergoes before joining the labour market and there is evidence to suggest female and most minority groups do better, so there is no difference in the skills acquired by the male gender as when levels of education are controlled in organisation there exists no significant difference between the male and female gender as well as minority groups managerial skills. Benis (1993) also argued that the only visible difference between the two genders is that the female has not learned to behave like the male gender or an adapted female. In an organisation, failure of the female gender to act in ways that is more efficient and harmonises with the ongoing culture of an instutionalised male manager, signals that the female manager cannot be trusted and is an outsider, this leads to a situation where recruiting of staffs and advancement of female gender relies solely on the male stereotype syndrome. (Burton, 1991). The glass ceiling situation is further strengthened by perception of thinking and organisational psycho-structures which are mainly stereotyped to the male gender (Cotter et al., 2001). These values of male stereotyping and exclusion of the female gender from management builds barriers over time and are a major hindrance to the progression on the career path of talented women and minority groups. Discrimination in Nigerian workplaces on the basis of gender has gathered a lot of attention, and this could be made manifest in preferential treatment, harassment, and victimisation (Trentham and Larwood, 1998).

In a research conducted by (Gibelman, 1998) it was discovered that management roles have over time been modelled to fit the male gender personality, only in some cases women are given promotions based on their demonstrated ability, and then the issue of what constitutes power comes up as it is viewed differently from both gender. In Nigeria, a former female speaker at the Federal House of Representatives was impeached on grounds that she awarded a contract which was ambiguous. After her impeachment, this same contract was awarded at a higher amount ro a male contractor. Also, in one of the northern states, a female member of the state house of representatives was given a one year suspension as she 'dared' to summon the house for taking a decision without her being present (Vangaurd, 2013). There are also cases of females being excluded or victimised from top positions despite being qualified. This male stereotyping has indeed been adduced to historical facts that male genders are able to hold power for a longer time and are free of child bearing and all the decision making hassles of the female gender (KoracKakabdase and Kouzmin, 1997).

\section{Commitment to work and gender distinctions}

Through an organisational culture on behavioural differences between the male and female gender, employers have a belief that women are less committed 
to their jobs as there exists a tendency to quit in other to fulfil family obligations and recently, organisations are less likely to invest in female gender; but in fact this is not true as studies have shown that the drawback is due to lack of opportunities available to them as women are becoming dissatisfied by lack of flexibility and recognition in their needs and talents (Dreher, 2003). For minority groups it becomes different as direct and indirect discrimination is used as tools against them in forms of sexual harassment, victimization, this greatly hinders their tendency to be less committed to their jobs as it causes low self esteem as it affects the employee psychologically (Vaughan and Hoggs, 2008).

\section{Wage differences}

Wage differences in work places has to do with the relative differences in earnings between males and females. In Nigeria, UNDP (2009), observed that the inequality in wage differences increased between 1980 to 2008. Despite having vast resources and the government being the largest employer of labour, Nigeria still ranks among the world's unequal nations in terms of gender equality. Poverty which is wide spread has being adduced to manifest in unequal income distribution and this could affect women and minority groups alike (Fapohunda 2013). According Correll and Bernard (2011), gender pay differences is not unrelated to scope of reconciling work, family life, discrimination among other factors, and work segregation. Looking at this gender pay differences form another angle, a greater percentage of women tend to work on part-time basis, which usually involves lesser pay than full-time jobs, and the tendency to leave the labour force as issues of child birth and care increases as they progress on their jobs (Boushey, 2007). Gender pay differences could arise from occupational segregation in relation to male dominated jobs, flexibility of job roles, power in negotiating salaries and gender stereotypes. In terms of occupational segregation, Soetan (2002) noticed that over $50 \%$ of Nigerian women tend to engage in clerical, health care, teaching professions and social care, and as such are under represented in engineering jobs, managerial jobs, medical jobs as well as production jobs. For flexibility in job roles, women are more likely to choose flexible jobs over the rigid ones as it will afford them the opportunity to better manage work and family issues. Conscious of gender stereotypes, women are less likely to negotiate on wages. Olagbeji and Afolabi (2004) found that men aggressively negotiate more than women.

\section{Mentoring}

Maume, (1999) observed that Lack of female mentor in organisations have also accounted for the continued manifestation of glass ceiling on female gender, it can be noted that this is the opposite in male gender as mentoring organisational relationships foster transition into management for young male employees. Eventually, if a female employee rises to top management position, the problem of support from other female colleges comes into play (Leephart and Schumacher, 2005). Maume, 1999 further observed that male under representation in female professions worked for them as they regularly interacted with their fellow male supervisors sharing interests. This has accounted for their dominance in organisations.

\section{Organisations accountability for women and minority groups}

Most organisations fail to include females in probable programs where identification of potential candidates who they believe can make good managers are spotted and Gibelman, 1998 links this to an organisational culture that believes women fear succeeding and may not be able to cope with managerial positions as well as family commitments. Most organisations do not take records or are ignorant to track the number of females or minority groups that take part in high potential programs or create a fair mix or both sexes and groups, this makes it possible for the continued stereotyping of managerial attributes to the males present and in the long run, get in the way of advancing career women as well as minority groups (Cotter et al., 2001). Organisations think of future managers and supervisors as males or adapted few females because of the traditional norm that exists in the company so it faces problems of no standard procedures for identifying suitable candidates for managerial positions (Leephart and Schumacher, 2009). Also, glass and concrete ceilings is made manifest through leadership in organisations due to over emphasis on competition rather than collaboration from both sexes and minority groups (Dreher, 2003).

\section{Workplace Environment}

Despite the importance of equality between genders and minority groups in workplace, there exists a wide range of complex issues that arise from workplace disclosure in the organisation; this has made access to resources and power still largely determined by sex, class and race. Lack of equality in treatment of these groups exists in organisations as it has not extensively implemented policies that attempt to adjust the position of females in work place (Strachan and Burgess, 1998). Organisation fails to get to the roots of gender and minority groups inequality and the usual case is allowing women to adapt themselves to the male managerial norm, in doing this the females encounter barriers created by the 
organisational work place and male managers with some female managers inclusive do not recognise their achievements (Korac-Kakabdase and Kouzmin, 1997). In the past two decades, due to the dissatisfaction of females in workplace, organisational policies have been implemented to adjust the position of women and minority groups in work place, having seen these groups as deficient and needing help, but these processes of ensuring equality in work place engenders hostility from dominant males since women benefit from these special treatments (Strachan and Burgess, 1998).

\section{Contributory factors to women's discrimination in Nigeria}

There are different complimentary factors that have created a fertile ground for gender discrimination to proliferate in Nigeria. Although these factors are interrelated; they are different to some extent. These factors, termed antecedents to women's discrimination are discussed below:

Cultural and Societal factors: A woman is regarded as second or minor to a man and are expected to perform all domestic chores. Early marriages and women with some form of formal education are saddled with responsibilities that make it difficult for women to improve themselves. Moreover most families in Nigeria encourage male children to be more aspiring than female, coupled with the fact that women have ascribed a division of labour to themselves ( for instance, women would rather take care of the home).

Religious constraints: Some religious practices limit women. For example, purdah (Moslem), early marriages and extreme submission (Christianity) with a theological root imbedded in the Holy Bible. Religious books have affirmed that the men are the head. For example, the honour of a Moslem family is represented by the purity of its women. Since education and career is liberating, it is believed that the liberating effects may contaminate the purity of women.

Biological constraints: This factor is always provided as evidence to support discrimination against women. In describing women's anatomy, Freud (1933) argued that the female reproductive system is an exonarable vise that keeps women emotionally unstable, submissive, passive and devoid of creative intellectual potential. For instance, pregnancy and childbirth makes them sometimes unfit for occupations that are rigorous. Hence, the divided loyalty between a woman's anatomy, work and home will have an adverse effect on her career. Although this factor has been disproved in different studies (Orubu 2014, This divided loyalty can lead to role conflicts and low participation in paid employment.

\section{Preventing gender discrimination at work}

The onus of preventing women's discrimination at work is on the lawmaker and employers are large. The national policy makers and necessary law enforcing agents should ensure that all policies from the recruitment to the hiring, compensation and benefits do not violate the employees' rights. Strict actions and sanctions should be taken by the federal and state government and management of the organisation against violators.

\section{More awareness}

The relegation of women into certain occupations and bottom occupational levels is as a result of the primary status of women as mothers; secondary bread winners to men; less geographically mobile and large reserve of employable women means supply will exceed demand and organisational's rules and statements. Limiting women economically is a violation of their rights, coupled with the facts that women are still contributing significantly to the socio-economical development of Nigeria irrespective of the occupational restriction they are exposed to. This has now made employers of labour and government agencies both at federal and states level to derive special measures to promote gender equality. For instance, the introduction of flexi and part time working pattern for women; the establishments of daycare centres and crèches within office premises and hospitals, in order to help women cope with their families and official responsibilities are getting more popular in Nigeria. Government at all levels are combating discriminatory traditional practices against women such as early marriages and the institutionalisation of their domestic roles. Other measures aimed that empowering women economically and socially include the provision of microcredit; establishment of women's cooperative societies in rural areas; establishment of skills-acquisition centres throughout the states and the setting of targets for women's economic advancement in the National Economic Policy. These entire positive moves toward eradicating the discrimination of women are complemented by a continuous and sustained sensitisation and advocacy programmes, resulting in a modest decline of discriminating against women in paid employment in Nigeria.

\section{Evidence}

At present, forces such as discrimination and harassment at work places have greatly hindered women employability. This is in part, linked to cultural and social values such as functional education marriage and responsibilities involved. From the table (table 1) it is seen that the female employment rate has been growing slowly since 2000 , although the male employment rate 
Table 1. Gender, Employment and Unemployment rate in Nigeria.

\begin{tabular}{|c|c|c|c|c|}
\hline Year & Male & Female & Male & Female \\
\hline & \multicolumn{2}{|c|}{ Employment Rate } & Unen & t Rate \\
\hline 2000 & & & 13.1 & \\
\hline 2001 & & & 13.6 & \\
\hline 2002 & & & 12.6 & \\
\hline 2003 & & & 14.8 & \\
\hline 2004 & & & 13.4 & \\
\hline 2005 & 57.3 & 44 & 11.9 & \\
\hline 2006 & 57.5 & 44.1 & 12.3 & \\
\hline 2007 & 57.7 & 44.2 & 12.3 & \\
\hline 2008 & 57.9 & 44.2 & 12.7 & \\
\hline 2009 & 58.1 & 44.3 & 14.9 & \\
\hline 2010 & 58.3 & 44.4 & 19.7 & \\
\hline 2011 & 58.5 & 44.5 & 21.1 & \\
\hline 2012 & 58.6 & 44.6 & 23.9 & \\
\hline 2013 & 58.8 & 44.7 & & \\
\hline 2014 & 58.9 & 44.7 & & \\
\hline 2015 & 58.8 & 44.6 & & \\
\hline
\end{tabular}

Source: National Bureau of Statistics, 2015

Table 2. Percentage of education by gender

\begin{tabular}{lcc}
\hline Year & Male & Female \\
\hline 2000 & 82 & 67 \\
2001 & 82 & 67 \\
2002 & 82 & 67 \\
2003 & 82 & 67 \\
2004 & 82 & 67 \\
2005 & 82 & 67 \\
2006 & 82 & 67 \\
2007 & 82 & 67 \\
2008 & 82 & 67 \\
2009 & 82 & 67 \\
2010 & 82 & 67 \\
2011 & 77 & 72 \\
2012 & 80 & 77 \\
2013 & 81 & 75 \\
2014 & 78 & 72 \\
2015 & 72 & 68 \\
\hline
\end{tabular}

Source: Education Policy and Data Centre 2015

has been fairly constant. This can be linked to the economic hardships currently being experienced (CBN, 2014). in terms of unemployment, more females have been out of work or have had no work as the female unemployment rate has declined at a rate of $0.3 \%$ each year since 2005.

Education arms an individual with marketable skills needed to reduce poverty. But this area has been under exploited in Nigeria as it is evident from the budgetary allocation (CBN 2014). Educated males up to tertiary level is more than females, (see table 2) and educated females rate has been fairly constant up till 2010, then was on the increase till 2014. 2015 recorded a decline in female education. This could be adduced to economic decline in recent years. In a survey by education policy and data centre, more females end up being out of school than males in Nigeria (See table 3).

The political scenario has not been left untouched by the glass ceiling, as since the inception of democracy in 1999, female participation in politics has been low Maclosky (1968) defines political participation as a voluntary activity shared be members of the society in selection of their rulers. Several factors including low funding, cultural factors, mentoring, women perception of politics, absence of self confidence and self inflicted glass ceiling has being identified as factors inhibiting women participation in politics. In Nigeria, female participation in politics has been low (see Table 4) as there has been no female President, or Governor.

\section{CONCLUSION}

The paper has been able to establish that gender political inequality and women's political underrepresentation in Nigeria over years are pervasive. Also identified in the paper are the factors responsible for this poor state of women in work places, which is due to the invisible barriers that impinge on their participation or under representation in politics, education and workplaces.

Generally speaking, improving access to quality of education is something a country can invest in and expect rewards. Female education will increase social 
Table 3. Out of School rates presented with $95 \%$ confidence interval

\begin{tabular}{lccc}
\hline Gender & Lower Limit & Estimated & Upper Limit \\
\hline Female & 4171394 & 4456414 & 471433 \\
Male & 3549830 & 3833133 & 4116436 \\
\hline
\end{tabular}

Source: Education Policy and Data Centre 2015

Table 4. Participation of Women in Nigerian Elections 1999-2015

\begin{tabular}{|c|c|c|c|c|c|c|c|c|c|c|c|c|}
\hline & \multicolumn{2}{|c|}{ Presidency } & \multicolumn{2}{|c|}{ Senate } & \multicolumn{2}{|c|}{ House of Rep } & \multicolumn{2}{|c|}{ Governor } & \multicolumn{2}{|c|}{ State House of Rep } & \multicolumn{2}{|c|}{ LGA } \\
\hline & seats & females & seats & females & seats & females & seats & females & seats & females & seats & females \\
\hline 1999 & 1 & 0 & 109 & 3 & 360 & 12 & 36 & 0 & 990 & 24 & 710 & 13 \\
\hline 2003 & 1 & 0 & 109 & 4 & 360 & 21 & 36 & 0 & 990 & 40 & 774 & 15 \\
\hline 2007 & 1 & 0 & 109 & 9 & 360 & 25 & 36 & 0 & 990 & 57 & 740 & 27 \\
\hline 2011 & 1 & 0 & 109 & 7 & 360 & 26 & 36 & 0 & 990 & 68 & Nil & Nil \\
\hline 2015 & 1 & 0 & 109 & 8 & 360 & 14 & 36 & 0 & 990 & 72 & Nil & Nil \\
\hline
\end{tabular}

Source: Eme, 2015, Premium Times 2015, Vanguard 2015

and economic development and as such enhance human capital and in the long run, reduce poverty.

\section{References}

Burton C (1991). The Promise and the Price: The Struggle for Equal Opportunity in Women Employment. Contemp. Sociol. 21(5): 17 -23

Centre for American Progress (2010). Wage Gap by Numbers. Available [http://www.americanprogress.org/issues/2009/01/wage gap number s.html]. Last accessed $22^{\text {nd }}$ January, 2015.

Cotter D, Hermsen A, Joan M, Ovadia S (2001). Glass Ceiling Effect. Soc. Forces. J. 80(2): 655-682

Dreher GF (2003). The Effect of Sex Ratios and Work Life Programs on Female Leadership at the Top. Hum. Relations. J. 56(5): 547-562

Eduation Policy and Data Centre (2015). National Education Profile 2015. Avialable at: http://www.epdc.org/sites/default/files/documents/Nigeria trends 0.p df accessed 2 July, 2016.

Gibelman M (1998). Women's Perception of the Glass Ceiling in Human Service Orgainsations and what to do about it. Affilia. 13(2) : 147-165

Korac-Kakabadse N, Kouzmin A (1997). Maintaining the Rage: From

"Glass and Concrete Ceilings"and Metaphorical Sex Changes to Psychological Audits and Renegotiating Organisational Scripts -part 1. Women in Manage. Rev. 12(5): 182-195

Longo P, Straehey CJ (2008). Whack! I've hit the Glass Ceiling, Women's Effort to Gain Status in Surgery. Gender. Medicine. 5(1): 88-100

Maume DJ (1999). Glass Ceilings and Glass Escalators: Occupational Segregation, Race and Sex Differences in Managerial Promotions. Work. Occupat. 26(4): 483-509

Office of National Statistics (2010). Gender Pay Gap Narrows. Available at: [http://www.statistics.gov.uk/cci/nugget.asp?id=167] last accessed $22^{\text {nd }}$ January, 2015.

Strachan G, Burgess J (1998). Origins, Meaning and Application at Australian Workplaces. Intl. J. Manpower. 19(4): 71-84
U.S. Department of Labor (1997). The glass ceiling initiative: Are there cracks in the ceiling? Employment Standards Administration, Office of Federal Contract Compliance Programs.

Vaughan GM, Hogg MA (2008). Introduction to Social Psychology. $5^{\text {th }}$ ed, Pearson.

Work Life Company, 2010. A Glass or Concrete Ceiling? Available at: [http://www.theworklifecompany.biz/A\%20Glass\%20or\%20Concrete \%20Ceiling.pdf]. Last accessed $22^{\text {nd }}$ January, 2015. 